\title{
INY RYBÈ RTIDYY
}

\author{
WAHUKA, ${ }^{1}$ Sinvaldo Oliveira \\ Pesquisador da Ação 'Saberes Indígenas na Escola'
}

\section{TURYBÈNA BUTÈ}

Iny rybèrèny hèka nawitxiramy namyhỹde iwitxira bdèdỹỹnana nalòmy namyhỹdeki, irbi tahè iòraruki iny rybèrèny rexihukèhè aõkõre, iny rybèmy rkarybèmyhỹrènykè, kièmy dori rybè tuu rybè õki rùsakè, iwsèki hèka hỹỹna mahãdu rybè rùsamy ramyhỹre. Hỹỹna mahãdu rybè wiji iny mahãdu rièryõmyhỹre, wiji hèka rybè sõèmy rawitxira witxiramy nyimyhỹde Hỹỹna rybè rùsamy rỹira, Iny Umy rybè ibutelemy iny tuu rarybèmyhỹre, wijina bòdu rybè-sỹ iwitxiramy nyimyhỹde Jyrè mahãdu rybè rbi. Mytahè rybè tuu rybè-õki rùsakè, rybè hèka rùrùmyhỹre myrèrimy aõnaõna iny birè birèmy rỹira timykèkibo rùsakè, òwòru òwòru-ni boho boho, butumy aõnaõna-ni.

Rybè wèryna: Hỹỹna rybè. Iny Umy rybè. Wijina bòdu rybè. Jyrè mahãdu rybè.

\section{RESUMO}

As falas do povo Iny vêm se diferenciando de acordo com as transformações e conhecimentos interculturais, mas não é por isso que devemos deixar de usar as palavras que têm raiz aprofundada na nossa cultura. As falas dos ancestrais, as falas dos mais velhos dos iny atuais, as falas dos jovens e as falas dos adolescentes na prática são diferentes. As falas dos ancestrais quase ninguém usa, ou não sabe mais. As palavras que não são usadas, elas vão morrendo devido ficarem paradas no tempo. E assim são as falas dos mais velhos, dos jovens e adolescentes se não praticarmos no nosso dia a dia. Elas vão perdendo espaço para outras formas de falas, inclusive nomes de toda a natureza que estão em nossa volta, árvores, pássaros e animais em geral.

Palavras-chave: Fala dos antigos. Fala dos velhos(as). Fala dos jovens. Fala dos adolescentes.

1 Rede UFG/UFT/UFMA. Professor de Educação Básica. 


\begin{abstract}
The speeches of the Iny people have differed according to the transformations and intercultural knowledge, but this is not why we should stop using words that have deep root in our culture. The ancestors' speeches, the speeches of the older of the current iny, the speeches of young people and the speeches of adolescents in practice are different. The ancestral speeches almost no one uses, or does not know anymore. Words that are not used, they will die because they stand still in time. And so are the speeches of the elders, the youth and adolescents if we do not practice in our day to day. They are loosing space for other forms of speech, including names of all nature around us, trees, birds, and animals in general.
\end{abstract}

Key words: Speech of the old. Speech of the old people. Speech of the young. Speech of the adolescents.

Kiamy ãkorèny ãrelyykre, titxibo kai boho tèèrymahãtènyte, iny bohohè wiji iny rybèrèny nawitxira witxiramy namyhỹde ibdèdỹỹnanamy tahè ãrarybekre. Hỹỹna mahãdu rybèhè wiji rexihumy namyhỹde, ỹda, titxibo aõbo ijõ-ò taholamahãtènyte? Kõrehe. Iny umy mahãdu wiji tarybèdi rỹira, wijina bòdu mahãdu rbi iwitximy narybèmy nyimyhỹde, mytasỹ, jyrè mahãdu rybè iwitxiramy narybèmy nyimyhỹde iny umy mahãdu rybè rbi. Tuhè ãrarybekre Hỹỹna rybè, Iny Umy rybè, Wijina bòdu rybè, Jyrè mahãdu rybè wirbi iwitxiramy nyimyhỹde.

Betehekre aõboini rybè-õ rèwinyra bdè-ki tuu bobikre, hỹỹna mahãdu rybè.

\title{
Hỹ̃̃na rybèdỹ̃̃:
}

\begin{tabular}{|l|l|l|}
\hline Tatèri aõbohnyỹỹ & Watxibirè rùrùra & Mrari ratyhymyhỹkè \\
\hline
\end{tabular}

Kawsèhè rètèòsinyrèri waèrynale knyhỹ, kièmy dori sõèmy rỹira, tahè wiji iny mahãdu tuu rarybèõmyhỹre. Tai hèka iny rièryõmy rỹira rùsamy rỹimyhỹre tuu rybè.

Tasỹxè iny umy mahãdu rybèmy kaki ijõ butè ãritèòsinykre, betehekre biu-ki roirèri wselehè ratxirèri, tahè rawitxiramy knyhỹ.

Iny Umy rybè.

\begin{tabular}{|l|l|l|}
\hline Tatèri aõbohny! & $\begin{array}{l}\text { Òtuni sènadu inihè } \\
\text { rèmyra }\end{array}$ & $\begin{array}{l}\text { Riòrè lahi } \\
\text { ratyhymyhỹkè }\end{array}$ \\
\hline
\end{tabular}


Wijina bòdu mahãdu tahè aõtxi aõtxile rarybèmyhỹre, tasỹ titxibo rininimyhỹre tori wsèhèkỹle titxibo aõwna.Tasỹxè uladu mahãdu rybèra, kia tahè ikrèna irybè wimy riurinymy roimyhỹre, bdè-ò tuu bobikre.

\section{Wijina bòdu rybè.}

\begin{tabular}{|l|l|l|}
\hline Tatèri & Sènadu rèmyra & $\begin{array}{l}\text { Riòrè lahi } \\
\text { rahespeitamyhỹkè }\end{array}$ \\
\hline
\end{tabular}

Myknyhè rybè nauriurimy namyhỹde mahasỹxè ijõ ãriwinykre jyrè mahãdu rybè. Tahè iny tarybè ùrènana rièrymyhỹre ùriki tahè iny rybè tyhy rùsakremy namyhỹde.

\begin{tabular}{|l|l|l|}
\hline Aõhè? & $\begin{array}{l}\text { Viração sohoji } \\
\text { rèmyra }\end{array}$ & Iny tasogra rihespeitanymyhỹkè \\
\hline
\end{tabular}

Kawsèhè rybè rèwinyra tuu raholamyhỹre myna rèwinyra, kai boho tahè sõèmy rybè wimy raurimy rỹira bdiwinybènykè. Kièmy tai ãtxitèri rybè tyaki, ikyki, tuu tarybètèri myle. Myhè raholarèrimy wahãre, ihãre tahè ijõ waèryna-õ rỹirèri sõèhèkỹlemy.

Waijoirèny, iny rybè hèka rùrùmyhỹre iny rùrùmyhỹre wsele, òwòru rùrùmyhỹre wsele, aõnaõna rùrùmyhỹ wsè tyhyle iny rybè rùrùmyhỹre. Wiji iny mahãdu-di ãdètèhèmyhỹde, jyrè mahãdudi, irybèrèny nawitxiramy namyhỹde, tai tahè rahõtinymyhỹre 'timykbo ijasò knawinykre jyrè mahãdu rybè-di?' Tasỹ ijõ-my rahõtinymyhỹre alòbròna juhu rỹira-di, òwòru òwòru-ni rỹira, utura utura-ni butumy aõnaõna ni rỹira. Timykbo tanarybèmahãtènyte myỹhè aõwna rahõtinymyhỹre, taikny kaa rybè butè rèwinyra idi mohõtinykremy kai kaa idi tariatèri uri idi mohõtinykremy, titxibo tuu tahõtinymahãte wawsè tyhyle.

Tiubo wasỹ-ki ijasò wiu-ò raholawahã, Tamyhè wiu-ò, kiamy irybè-ò raholare, 'talawò ijori tbymy' tasỹ ijõra 'txu-di ole bdè ribinanyre' kahè hỹỹna mahãdu rybè rarekre, wijina mahãdu ta tiu rièryõtyhy. Mykiè warybè butè ãdèèrèny. Kawsè iny rybè-di wiji nadètèmyhỹde timykèkibo iny rybè rexihukè iwsè hèka iny hỹỹna aõmydỹỹnana rexihure, iurèdè õki, ijè, òluò urèdè wiji ixãwimy roimyhỹre, titxi iny tuu tobixiõna ièrydu ratxikè ijõõre iny tyaki tiièmy rùsamy rỹira, tyyrti ube-kile titxibo aõwna iny tuu kdobikè. Iwsè tahè aõnaõna ni rỹira rexihukè tuu rybè-õki iurèdè õki, tori 
rybèhè iny boho aõnityhymy riuhèmyhỹrènyre tarybè rbi òtu aõ kia rininimyhỹre tori rybèhèkỹlemy. Hãriiri iny wiji rininimyhỹre tori rybèhèkỹlemy, aõ wna titxibo ini rièryõrèri iny-õ ijõ tahè titxibo tuu worè-lemy tuu rininimyhỹre tori rybè-my.

Kawsèhè waijoi mahãdu iny rybèrènydi nadètèhèmyhỹde, ùriki tahè tiièmy rybè bdèdỹỹnana tarèhèmy rawitxira witxiramy ramyhỹre aõ rybè irù-my rỹira rùrùkremy aõkõ knyhỹ ùrile rahonanykremy rybè iwsèki rasõèmyhỹre ityhymy dèlèmyhỹde. Myhè rahõtinymyhỹre iny rybè ratyhymyhỹkèmy, rauhèmyhỹkè iny umy rybè, iwsè-ki tiu iny rybèrèny rùsaõtyhy tasỹxè tori rybè-my rybè aõtxiki iny tuu rarybèmyhỹkè tamyrèny xièry òbitityhy. Iny boho widèè irybèrènymy rarybèmyhỹre ta awiõre iny boho tarybè òbiti rirbunymyhỹre tuu rybèõki, irè iny tarybè rirùbdènyrèri tiièmy, iwsè kièhèka raholawahãre, nyrỹhỹkỹ, exihikỹ-my rybè ixãwikremy osny namyhỹde kièmy ijõ iny primo, ỹda, prima myhỹkỹle widèè ryrymyhỹre, kiahè iwsèki tarybè rirbunyrèri, awi aõkõ knyhỹ iwsèki riwinyrèri, iriòrè tuhykyle knarybekre.

Myhèka rybè rexihumyhỹre iurèdè dỹỹõki taihèka iny boho tarybèmy rarybèmyhỹkè ùrikõmy rùsahèny. Iny mahãdu hèka wiji tabdèdỹỹnana-di rehukrelemy nyimyhỹde ixỹju aõmydỹỹnanale tahè aõnityhymy wiji natyhydỹỹmyhỹde kaa hèka warayky mynamy tuu rarybèri iwsèmy ãdètèhèmyhỹdemyhỹ, tahè wawsèmy ixidi bdètehekre wna tule iximy bdobikre, rybè-ò bdoholakre tahè bdierykre. Iny hèka aõ kia rièryra ixidi rètèhèrèrimy aõ riòtdunyramy bdè rièrymyhỹre, myrèrimy knyhè iny bdèdỹỹnana-di nadètèhèmyhỹde kawsèmy.

Iny rybè bdèdỹỹnanahè kawsè rèèrymy tuu ãkorèny rèryryrèri, hỹỹna mahãdu rybè, iaõmydỹỹna rùsamy roimyhỹre. Iny umy mahãdu rybè tule, urikixe awilemyhỹre kièmy dorituu rybèdu nyilemyhỹde, tahè tii bohole turybèdumy ratximyhỹrènyre. Tasỹ wijina bòdu mahãdu irybèrèny iwitxiramy nyimyhỹde, iwsè tahè jyrè mahãdu rybè-sỹ rỹira butu rbiiwitxiramy. Biu-ki tuu rarybèra tasỹ ixby kaki tuu rarybèrèri.

Wijina bòdu mahãdu rybè tahè aõma rare iny tmyra tarybèmy rarybèmyhỹre, ijõhè tiu iny umy mahãdu rybèmy rarybèõhykymyhỹre, rybèdỹỹ-kihè tutyhyre, tiu òbitimy ròrybèdỹỹõmyhỹre. Ihãre tasỹ irybè tyaki sõèmy tori rybè ijõdikre, tuu hèka irybèrèny-ò raholawahãre, kiahèka rybè-ki turèri, aõdỹỹxina tahè iny rybè rti-di riraki, tiu òsny idi rariaõtyhy, kaa tyyrti rèwinyrèridi tiu kia iriraõna, kièmy tori tyyrti-di rira-le aõnityhymy rièryrèri, tarybè rti-di rira tahè 
tamy isirarèri myhèka rabirèrimy wahãre. Iny rybèrèny dèòsamy namyhỹde, tai wahè, tuu rybèõki, iurèdèõki. Jyrè mahãdu rybè tahè ièrènakre, wijina mahãdu rybè, uladu mahãdu rybè tiiètyhymy iny umy mahãdu rybè rbi iwitxiramy ròhònykre, hỹỹna mahãdu rybè tahè tiu ièrysyõna kièmy tiu tuu roholaõmyhỹre tai hèka tùre, kièmy iny kymy wiji rỹira ni-le rièryrèri, aõnaõna tori rbi namyhỹde ni-le, tii-le tamy irutaõrèri, kièmy txuõtxuõmy tuu rarybèmyhỹre, TV-di rètèrèri myle irybè tahè tamy itnyrèri, myhèka jyrè mahãdu rybè rỹira.

Kièmy dori uladu mahãdu aõ-ò roholamyhỹre myna rarybèrèrimy ihỹre, aõmy robimyhỹre myna aõ kia riwinymyhỹre, myhèka uladu rỹira, ixinamy ixidèèwimy aõ kia rierykre, iurènana tahè jyrè mahãdu rybè iwitximy namyhỹde tai hèka tyyrti bdèdỹỹnana awire, iny rybè rtidỹỹ, idi rira boho boho, wiji hèka tyyrtidỹỹdu mahãdu hỹỹna rybè sõèmy dirtinymyhỹde dỹỹraximyhỹdemy iny umy mahãdu-ò, wiji hèka rybè hetxina mahãdu nartimyhỹde tyyrti ùbe-ò, irùtaõlemy iny tai knahakremy. Mykny tyyrti iny boho sõèmy rkièryrènykè iny rybè rti, idi rira boho boho, kièmy iu sõèmy rybè iny boho rkièryrènykre, rybè hetxina, rybè tmyra myle.

Ihãre tasỹ iny bohowii rkiwiòhènanykre hỹỹna rybè bdèdỹỹnana-ki iny widèè knarybekre ijõ rybè taèrynamy, iu tahè irè rybè rasõèkre, tuu hèka rkatximyhỹrènykè iny rybè èrymy, idi rira èrymy, irtidỹỹ èrymy. Kawsè hèka inydirèny rahõtinymyhỹre iny rybè rtidỹỹ butumy rkièrymyhỹrènykèmy, iu hèka iny rybèrèny tiu rexihuõtyhy, tiu tùsaõna, kièmy dori tyyrti-ki kdoikre butumy iny-õ tibo rièryõkè tamyle riijekre tori mahãdu rỹira wsèmyhỹ. Iwsèki hèka iny tmyra mahãdu dori butumy kdierykre ihãre tasỹ iny rybè rityhynykre, kièmy dori wiji nadètèhèmyhỹde iny tmyra mahãdu, wijina mahãdu, iny rybè rityhynyõmyhỹre tuu juhu rarybèramy, tori rybè-le aõnityhymy dityhynymy nyimyhỹde taikny iny rybè rawitxiramy namyhỹde.

Timybohè iny umy mahãdu dètèhèmyhỹde idirèny, ùrikihè titxibo wawsè-le dobimyhỹde, aõ wna rahõtinymyhỹre juhu iny ỹnyramy ramyhỹre tahãwyy wna, tariòrè boho wnakia tahè tiobo rakre rièrymyhỹre, ỹnyra ni, ijòti ni aõtxile tiòbo ramyhỹre ni rièrymyhỹre. Kia tahè tariòrè dèè aõnaõna rỹira ritèòsinymyhỹre aõtyhytyhybo rỹirèri, tasỹ taina boho ni-my tamy rarybèmy rỹiramyhỹ, tariòrèko relyymy rỹiramyhỹ iurènana ta juhu uladu mahãdu bdè rièrymy rỹiramyhỹ butumy taina mahãdu ni rièrymyhỹre, ijòti ijòti ni, ỹnyra rỹira ni, tòla tòla ni rỹira boho boho juhu iny rièrymy rỹiramyhỹ.

Tasỹ juhu iny mahãdu hãwò-di rirahùmyhỹre iùrènana ta butumy bdè bdè rièrymyhỹre, kièmy ywimy ramyhỹre bero-di. Wiji 
tahè tuu aõkõ wijina mahãdu rỹira aõtxi rakre wna ixiõhidỹỹmy hèòty-dile kia titxibo rakre, tasỹ aõ wna tỹhimy aõkõ ramyhỹre, aõ wna ixirelemy ramyhỹre, tatxunalemy ròòsèmyhỹre, myboho boho tahè iny rybè bdèdỹỹnana-ki ijõmy rexihumyhỹre irùrù rabutèmy ramyhỹre. Iny bdèdỹỹnanarèny, lsina boho boho rỹira iurèdè õki ixãwikre. Kièmy aõ tetxiki roirèrimyhỹre retbymyhỹre, iwsè ta iny rybèrèny rỹira, tuu rybè õki rùsakè.

Oworu bdèdỹỹnana-disỹ ijõmy rahõtinymyhỹre, iny alòbròna rỹira-di, ini mahãdu timy kbo aõwi rỹira tani-di, rawitxiramy aõkbo nyimyhỹde myhè rahõtinymyhỹre, tasỹ ijõra, nawii ãhu-my rỹira mahãdu ni, iròdu iròdu ni tule, butumy aõnaõna ni rỹira-di rahõtinymyhỹre ijõhè rùsakremy rỹira, ijõ tasỹ iny-õ rièryõhykymyhỹre myhè inydirèny rahõtinymyhỹre.

Tasỹ ijõmy rahõtinymyhỹre, Berohokỹ rèhè rara hèka juhu iijòti inidilehekỹ rỹira, ỹnyra kia rara tule, bero smo smo rỹira iny ni ijõdimy rỹira, wiji tahè aõtxiki ijõ iiny nidimy rỹira ijõhè tiiètyhymy ièryõna rỹira, iiny ni rayxènymy rỹira, rùsamy, tuu rybèõki hèka rybè rùrùmyhỹre tiièmy.

Tasỹ ijõmy rahõtinymyhỹre wyhy widỹỹdi, waxiwahatè iny riwinymyhỹre boho boho-di, wyhy isyra tyhyre, aõ isirarèrimy aõkõ knyhỹ, urile tahè iaõmydỹỹna sõere, juhu iny rimymyhỹre wyhy riwinykremy btòrè, tahè iry hèòty-ò ritòtèènymyhỹre iry raòbitinykremy, irbi tasỹ iuni iny riysèmyhỹre btòrè-ry budè myna rèakremy, tahè tỹtè-di iny ritỹtènymyhỹre juhu tahè tbòtèrè-diwyhy uni ritdynymyhỹre hèòty-ò ritòtèènymy knyhỹ itỹtèna rimykremyhỹ.

Kahè rexihukèwsè roira, tahè rasiranyra te widỹỹ, ihãju widỹỹ myle, wyhy de-my rèlèmyhỹre iny juraha-my rininimyhỹre, ùriki tahè nawii de-le ihỹre. Tahè tuu rèlèmyhỹre nawii de wideewokèhè aõkõre. Juhu iny tawyhy riwinymy rỹiramyhỹ tõrati rahy yjymy riwinymyhỹre iruxeramy, kiahèka wyhy ijõdire, tee, iuni, tasỹ tuu rarybèõra, ihãju, wyhy hãju-my rèlèmyhỹ utura dèòhu, broreni ti ijõmy tuu rèlèmyhỹre. Tahè iny ijõdikre bdèò ãritèòtènykre bierykremy.

\begin{tabular}{|c|c|c|}
\hline Btòrè & Wyhy uni & Juraha \\
rarytòmyhỹ & Iuni raòbitimyhỹre & Tee relekre: rauhekre; \\
hèòty-ò & hèòty-ò, rauhekre: & òkrèsyna, tòmatèrè sò, \\
taihè ijõdikre: & hèòty, may ihãju, & tbòra, èsõ, iura, ilby \\
hèòty, may & tbòtèrè, èsõ & \\
\hline
\end{tabular}


Kawsè hèka iny wyhy riwinymyhỹre, wiji iny tawyhy hãju-my diwinymyhỹde tahè arami ti-le ihỹre, brèu ijõmy tuu riwinymyhỹre. Mykny hèka ijõmysỹ rahõtinymyhỹre, wyhymy wiji nadobimyhỹde-sỹ tòmatèrè sò ijõõmyhỹre, juhu ta wyhy tõrati sò-my rỹiramyhỹ. Tbòtèrè-sỹ wiji iny mahãdu tori-my rỹirale tuu riuhèmyhỹre, juhu ta hàri bdi noijò tuu riwinymy rỹiramyhỹ, myknyhè iny bdèdỹỹnana roimyhỹre juhu rỹira ixãwimy namyhỹde ihyky timykèkibo rexihukremy inihi. Ibinamy knyhỹ kièmy dori ixihèki ridykre ijõmy tuu rybè, rybè ijõmy rùrùkre iwsè hèka rybè rùrùmyhỹre. Kaa hèka wyhy aõmydỹỹna-kile tuu ãdèèrèny rarybèrèri ihãre tahè sõèmy rỹirèri iny rybè timykibo rùsamyhỹre bdèdỹỹnana, kakny waxiwahatè-my rarybèõhyyra tuu rèlèmyhỹremy, tu ta inisỹ ãrarybè timybo rèlèmyhỹremy, urikihè waxiwahatè-òle tuu rèlèmyhỹre, hòròtò tahè inityhyre.

Iny-hè aõtxile aõkõ hòròtò-ò waxiwahatè-my relekre riòròmyhỹre, juhu itky riysèmyhỹre itky iyjy rùsmo wnahè riòròmyhỹre tii hèka waxiwahatè-ki awikre, tasỹ iny riijèmyhỹre hòròtò irarùna, iumy, ihetxina, hòròtò tmyra ta awiõre tmo aõkõ raixinymyhỹre, ijõ raòròmyhỹre myle, mykny hèka waxiwahatè rèlèmyhỹre aõ uritrè aõkõ. Tasỹ tèòrèrù-my rèlèmy rỹiramyhỹ juhu, ãsu-ò nora, ãsu-ò tmyra nobtò tuu rèlèmyhỹre, ãsuramy raninimyhỹre, ãsura hèka ãsu itmyramy rỹirèrimy ihỹre tuu raninimyhỹre, tõbtò tahè iny riòròmyhỹre tahè riynymyhỹre, juhu tyhy iny riysèmyhỹre irahudi tahè iny riynymyhỹre, tõrana rỹimyhỹre myna myna hèka iny riynymyhỹre irahudi tahè bdètòtèè-ò rihãwimyhỹre rarbukremy, rarbumyhỹreu tahè iny rirèrùnymyhỹre, waxiwahatè dèòrèrù-my. Myknyhèka iny bdèdỹỹnana rỹiramyhỹ, wiji taòsny iny riwinyõmyhỹre aõ wna rièryõmyhỹre myle.

Titxibo iny-õ rarybèmyhỹre iny-my ratxirèri-ki butumy tabdèdỹỹnana rièrymyhỹremy ta aõkõre, tiu iny butumy tabdèdỹỹnana rièryõmyhỹre wiji ièrèna tyhy tori-my iny bdèdỹỹnana raurimy roimyhỹreki wijina bòdu mahãduhè aõdỹỹxina. Iny umy mahãdu tahè titxibo ijõ iny tabdèdỹỹnana-di rièrytyhyhykỹlemy ratximyhỹre aõ butumy rièryrèrimy aõkõ knyhỹ kièmyhè hỹỹna mahãdu bdèdỹỹnana iny brysiki ijõ rùsamy rỹira, iny rybè-ki tule. Myhèka iny rỹira, bdè rawitxira witxiramy ramyhỹremy ta iwsè-le iny boho ihèki ramyhỹre rawitxira witxiramy, kiale tahè ibinamyhỹre rybè iuredeõki rayxènykrele, oworù rayxènymyhỹre wsèmy, ihyky ta retbymyhỹre iwsè tahè iny rybèrèny roimyhỹre. 
Butumy kaki ãkorèny relyyrèri, rarybèrèri, rèrtinyra aõ rùi aõkõ ratxirèri kièmy dori ijõmy dỹỹraxi rèwinyre ibdèdỹỹnanamy tahè iny-õ kawsè rarybere tai kny kaki tuu rèrtinyra, iny mahãdu idi rariakreu tuu idi retehekremy iu tahè irèhè-ò kdetehekre tako-ò,ỹda, tahewo-ò aõbo kdetehekre, kièmy dori uladu mahãdu-my kdobikre, aõ wna ixidèè irybè kdiwinykre myle, timybo knarybekrehe, taihè tahewo-ò itxèrèmy rarybèrèri, kièmy dori inyheworènymy kdoikre, iny boho tahè ikorènymy ramyhỹre iny korèny-ò aõbo roirèri iny boho rièryõrèri taikny tahewo-ò itxèrè uladu smo-my kdobikre ratxirèri, iny dori ixiko-ò aõ rièryõrèri.

Kahè rybè bdèdỹỹnanamy rarybèra tiubo tasỹ iwitxiramy anarybekre, tule knyhỹ rybè bdèdỹỹnana-lemy, kièmy dori idi aõnityhymy nadexiaõlkunymyhỹde iny rybè rtidỹỹ-di iny rybè rti-di rira boho bohodi myle, iny boho aõnityhymy rybè rtidỹỹ-ki tarybè rtidỹỹ rièryõre, rybè-ki tahè awirèri.

Aõmatxi rahõtimyhỹre irèhè-ò rybèna-di rarybekre-ki, kiata irtidỹỹki tarybèmy aõkõ kia rybè riwinykre tori rybèhèkỹlemy, tuhyky iny widèè rarybèmyhỹre tai tahè ijõ iny tèòsahakỹlemy ròwidỹỹmyhỹre kièmy irybè aõkõ ratxirèri, tahè raèrymyhỹre ihãrele, mykny iny ijoirèny-di rètèmyhỹre tai tahè idirèny rahõtinymyhỹre timykbo ratximyhỹrènyremy. Ijõhè tiiètyhymy tori rybè widỹỹ rièryõrèri, ijõ tasỹ tiiètyhymy iny rybè widỹỹ rièryõrèri. Mytahè tiòtiò iny rayky roirèri, iny hèka bjiu-ki wsè ratxirèrimyihỹre tiobo rakre hèka rexièryõhykyrèri, tahè ãdohotalemy rariakre, kièmy dorihè tori rybè ijõ iny rièryõre, tasỹ ijõ iny rybè rièryõrèri. Tai hèka ibinare tyyrti èryõ, tyyrti butumy iny rièrymyhỹre tahè awirèri kièmy irtidỹỹ òbitimy kdiwinykre, aõtxile iny rybè aõbo ỹda tori rybè aõbo aõtxile kdierykre iwidỹỹ.

Myknyhè inydirèny sõèmy rahõtinymyhỹre iny aõmydỹỹnana butumy rkièrymyhỹrènykè, tasỹ tule irtidỹỹ, idi rira boho boho rkièrymyhỹrènykè, ibdèdỹỹnana-kihè inatàhàhàkỹmy rybè rtidỹỹ raèrykè kièmy dori wiji tyyrtidỹỹdu nyimyhỹde iny rybè rtidỹỹ wiji òbitimy diwinymy nimyhỹde, dòèrynanymy nyimyhỹde awimy. Juhu tahè tuu aõkõ rỹiramyhỹ, iny rybè-di iny ritohonimy rỹiramyhỹ iny aõkõ rare, tai ta adohotalemy iny rybè riwinymy rỹiramyhỹ, wiji taxè tumyhỹde aõkõ rare, iny rybè òbitimy dirtinymy nyimyhỹde awimy knyhỹ inydèèrèny.

Kawsele warybè ãdèèrèny irbisỹ ijõ ãdiwinykre ãitxèrènarènymy, kadi ta mariabènykre tuu wiko belyybènymy, tibo tai awimy tahatamy marybèmy, widèè bitèòsinymy tasỹ tikibo tai 
ibinamy mahakre tule tuu marybekre ãbiòwa-ò bitèòsinymy, kièmy dori tuu iny aõ rièrymyhỹre idi rètèhèrèrimy, riòtdunymyhỹremy, irahudi tahè riwinymyhỹre, ijõ diryrymyhỹde, myhèka iny boho rỹira. Iny tiu hãwò-õ idi itxèrèõmy riwinyõtyhy, idi rètèhèrèrimy kia riwinykre. Kiamybosỹ ãkorèny relyyõra timybo hãwò rèlèmyhỹre bdèdỹỹnana-my, txiòtainisỹ ixby tyyrti-ò ãdiwinykre, kièmy dori kaa tyyrti woki sõèmy rybè ijõdikre. Mykiè ijoi mahãdu awimyhè akirèny rahara kai kadi tariata tasỹ tèèryta myle, aõ wna ãdèè awimy ròhònyra, ixby kdòhònykre tahè awityhykre karbi maha boholamy biraòmy mabekre, irèhèmy aõkõ kdòhònykre iòhòlemy.

Awihè rare tyyrti widỹỹ, tasỹ idi rira tule iny idi rira-ki irèhèmy wsèhèka ramyhỹre, ixidèè aõ kawsèle tuu dobimyhỹde, myhè tyyrtidi rira rare aõni awi taikiexe iny rybè rkièrymyhỹrènykèmy rarybèra, kièmy iu tarybè urènana iny widèè rarybèmyhỹkè rirtinymyhỹkè mykiè warybè adèèrèny, umy ãreàlàkre idi tariataki, tiwabiòwanyta, txiòtòètukè watyyrti-di tariata.

\section{REFERÊNCIAS}

LARIWANA, L.; PIMENTEL DA SILVA, M. S. A língua Karajá: empréstimos linguísticos. Revista Articulando e Construindo Saberes, v. 01, 2016.

PIMENTEL DA SILVA, M. S. Reflexões sociolinguísticas sobre línguas ameaçadas. Goiânia: Ed. UCG, 2009.

PIMENTEL DA SILVA, M. S. (Org). Epistemologia Iny. Goiânia: Editora Espaço Acadêmico, 2015. 
